\title{
CANAL TRANSPORTATION AND CENTRIC ABILITY OF FOUR DIFFERENT NiTi ROTARY SYSTEMS IN CURVED CANALS
}

\author{
Soliman M. Kamha*
}

\begin{abstract}
Aim: to study canal transportation and centric ability of four different NiTi rotary systems in curved canals.

Materials and Methods: forty extracted mandibular first molars with similar length and root curvature were selected. All teeth were accessed and working length determined. Teeth were embedded in heavy body rubber base impression material after cutting of distal root to the cervical level. The teeth were randomly assigned to four groups, ten for each. Group I was prepared with ProTaper universal up to F2, group II was prepared with ProTaper Next up to X2, group III was prepared with WaveOne up to primary file, and group IV was prepared with Wave One Gold up to primary file. All teeth were submitted to Pre and post instrumentation scanning with multislice $\mathrm{CT}$ and root cross-sections were saved and compared at three levels; $3 \mathrm{~mm}$ from the apex (apical), $3 \mathrm{~mm}$ from the canal orifice (coronal), and mid way between the two measurements (middle). Canal transportation and centric ability were estimated and statistically analyzed.
\end{abstract}

Results: there was no significant difference between the four groups in apical and coronal levels, but, in middle part, there was a significant difference between them regarding canal transportation and centric ability.

Conclusion: the WaveOne Gold NiTi primary reciprocating file maintained the original canal anatomy with less modification of the canal curvature compared with other file systems up to apical size 25.

KEYWORDS Canal transportation, centric ability, WaveOne Gold, WaveOne, ProTaper Next, ProTaper Universal

\section{INTRODUCTION}

Successful outcome of root canal treatment depends primarily on proper cleaning and shaping of the canal. Chemo-mechanical preparation is performed by physically removing infected dentin and facilitating the transport of disinfecting irrigants to the apical areas of the canal ${ }^{[1]}$. Canal anatomy and its curvature play an important role in maintaining the original canal shape and curvature after instrumentation ${ }^{[2,3]}$. Curved canals might present a challenge as a result of transportation ${ }^{[4]}$.

*Lecturer of Endodontics, Faculty of Dentistry, Pharos University 
Canal transportation, apical zipping, canal ledge, and strip perforation might occur as a result of deviation of the canal way of curved canal from its axis during instrumentation ${ }^{[5]}$. Excessive and inappropriate dentin removal, straightening of the canal, canals with hourglass appearance in cross section that requires stripping, over preparation that weakens the tooth resulting in root fracture are also resulting from deviation from the original canal curvature during instrumentation ${ }^{[6,7]}$. Alloys used in manufacturing instruments, instrument design, cross section, taper, and tip design can affect canal centric ability. Using stainless steel instruments in preparing curved canal frequently results in undesirable aberrations ${ }^{[8]}$.

Transportation is defined as "the removal of canal wall structure on the outside curve in the apical and coronal parts of the canal and inside curve in the middle part due to the tendency of files to restore themselves to their original linear shape during canal preparation" ${ }^{[9]}$.

Previous studies have shown that, canal transportation leads to inappropriate dentin removal with high risk of straightening of the original canal curvature and forming ledges in the dentin wall ${ }^{[10,11]}$. It has been shown that, this straightening of the canal during canal preparation leads to changes in working length ${ }^{[12]}$. NiTi rotary instrumentation may lead to a smaller WL change during shaping procedures ${ }^{[13]}$.

Introduction of $\mathrm{NiTi}$ rotary instruments can significantly decrease these procedural errors as compared with hand instruments ${ }^{[14,15]}$.

The superelasticity of NiTi rotary files may allow less lateral forces to be exerted against the canal walls, especially in severely curved canals, reducing the risk of canal transportation and better maintaining the original canal shape ${ }^{[16]}$.

NiTi instruments with less cross sectional area, less taper, more flexibility, and with non cutting tips show better centric ability ${ }^{[17]}$.
The ProTaper Universal system is a widely used NiTi rotary in clinic practice. Each file has varying percentage of taper over the length of its cutting blades in which can cut dentin more effectively, reduce torsional loads and produce increased canal transportation ${ }^{[18]}$

ProTaper next is the successor to the ProTaper Universal system. It has a patented, off-centred, rectangular cross section giving the files a unique, snake-like swaggering movement. This improved action creates an enlarged space for debris removal, optimises the canal tracking and reduces binding ${ }^{[19]}$.

Reciprocation, defined as any repetitive back-and-forth motion which mimics manual movement and reduces the various risks associated with continuously rotating a file through canal curvature ${ }^{[20]}$. The reciprocating motion of the NiTi rotary instrument has been shown to decrease the impact of cyclic fatigue compared with rotational motion ${ }^{[21,22]}$. Wave One NiTi single file is designed to be used with a dedicated reciprocating motion motor ${ }^{[23]}$.

Berutti et al ${ }^{[24]}$ concluded that, WaveOne NiTi Primary reciprocating single-file better maintained the original canal anatomy, with less modification of the canal curvature compared with the ProTaper system up to F2.

Both ProTaper next and WaveOne NiTi files are manufactured with M-Wire NiTi alloy which presented mechanical properties that can render endodontic instruments more flexible and fatigue resistant than those made with conventionally processed NiTi wires ${ }^{[25-28]}$. Because of the increased flexibility, the M-Wire NiTi alloy files may maintain the original canal shape better and minimize canal transportation in the curved root canals ${ }^{[29]}$.

WaveOne Gold is a new generation of reciprocating files that was introduced to the market. The system is supposed to offer additional benefits over its predecessor. Its raw metal is nickel titanium 
which is repeatedly heated and cooled, giving it not only its gold colour, but also considerably improving its strength and flexibility ${ }^{[30]}$.

Many methods and techniques were reported in the literature to study transportation and centric ability.

Plastic models were used in one study to evaluate the WaveOne instrument in curved canal. It was concluded that, WaveOne instrument had excellent centering ability with a low risk of fracture or blockage, reduced risk of aberrations and a short shaping time ${ }^{[31]}$.

Freire et al used cross-sectioning and microcomputed tomography in comparing Twisted File and EndoSequence systems and they found that, the two systems showed similar behavior regarding apical transportation of curved canals, with minimal transportation. They believed that, micro-computed tomography to be superior method ${ }^{[32]}$.

Lim et al ${ }^{[33]}$ studied the ability of the WaveOne and Reciproc instruments to remain centered in the prepared simulated curved root canals in clear resin blocks under scanning electron microscope (SEM) for topographic features of the cross-section. They found that, both systems possess an adequate centering ability.

Recently, Cone beam computed tomography (CBCT) has been specifically designed to produce undistorted three dimensional information of the maxillofacial skeleton, including the teeth and their surrounding tissues ${ }^{[34]}$. It was used for comparing instrumentation of different file systems. Protaper Next has better centric ability than Wave One and Protaper ${ }^{[35]}$. Dhingra et al ${ }^{[36]}$ concluded that, WaveOne NiTi files appeared to maintain the original canal anatomy and the presence of a glide path further improves their performance.

Newer machines now offer resolutions in the micron range and can be accompanied by more accurate measurement software with the capabilities of matching multi-dimensional data from specimens before and after preparation ${ }^{[36]}$. The amount and direction of canal transportation can be viewed at any level of the root length ${ }^{[37,38]}$.

It is important to compare the efficacy of different instruments during preparation of curved root canal with respect the original shape, canal curvature, centric ability, and preservation of dentin thickness with adequate cleaning of the root canal walls. This study was conducted to compare four NiTi rotary files (ProTaper Universal, ProTaper Next, WaveOne, and WaveOne Gold) and their effect on canal transportation and centric ability.

\section{MATERIAL AND METHODS}

\section{Selection of samples}

Forty extracted mandibular human first molars with fully formed apices were obtained from the tooth bank of Pharos University and stored in saline until use. The teeth were selected on the basis of their similar characteristics of length (19 to $22 \mathrm{~mm}$ ) and curvature degree (20 to 40 degrees) according to the Schneider method ${ }^{[39]}$.

\section{Preparation of samples}

The access cavities were prepared, and the MB canals were localized and explored with a size 10 K-type file (Dentsply / Maillefer, Ballaigues, Switzerland), which was passively advanced into the canals until the tip of the instrument penetrated and adjusted to the apical foramen. The real canal length was recorded, and the working length (WL) was calculated by subtracting $1 \mathrm{~mm}$ from this measurement. The teeth were embedded in heavy body rubber base impression material after cutting of distal root to the cervical level to facilitate preinstrumentation and post-instrumentation threedimensional CT images in the same position.

\section{Pre-intrumentation scanning}

All teeth were scanned by Multislice CT device (Toshiba, Aquillion one 640 slices, Japan) and the data were stored on a magnetic optical disc. 


\section{Canal Preparation}

The glide path was created for every canal with proGlider (size 16, 2\% apical taper)(Dentsply / Maillefer, Switzerland) to ensure more safety during the use of the first NiTi rotary file.

\section{Grouping}

The teeth were randomly assigned to four groups, ten for each. Group I was prepared with ProTaper universal nickel-titanium rotary system files. Group II was prepared with ProTaper Next nickel-titanium rotary system files. Group III was prepared with Wave One nickel-titanium rotary system files. Group IV was prepared with Wave One Gold nickel-titanium rotary system files.

\section{Group I}

The MB canals of this group were prepared by using the ProTaper Universal nickel-titanium rotary system (Dentsply/Maillefer). Instrumentation started with Shaping File \#1 up to the length corresponding to root curvature start. The SX file was used in a similar way at the length reached with the Shaping File \#1. Instrumentation was completed with S1, S2, F1, and F2 (size 25, 8\% apical taper) files to the WL.

\section{Group II}

The MB canals of this group were prepared by using the ProTaper Next nickel-titanium rotary system (Dentsply/Maillefer). Instrumentation started in the sequence X1 (size 17,4\% apical taper) file followed by X2 (size 25, 6\% apical taper) file to the WL at a rotational speed of $300 \mathrm{rpm}$ and $200 \mathrm{~g} /$ $\mathrm{cm}$ torque.

\section{Group III}

The MB canals of this group were prepared by using the WaveOne Primary reciprocating files (size 25, 8\% apical taper) (Dentsply Maillefer) using a pecking motion to the WL by reciprocating motor (Dentsply Maillefer) of the WaveOne.

\section{Group IV}

The MB canals of this group were prepared by using the WaveOne Gold Primary reciprocating files (size 25, 7\% apical taper) (Dentsply Maillefer) using a pecking motion to the WL by reciprocating motor (Dentsply Maillefer) of the WaveOne.

Canal patency was checked with a size10 K-file (Dentsply Maillefer) between every file used $1 \mathrm{~mm}$ beyond the apical foramen.

During instrumentation, the root canals of all groups were irrigated with $5.25 \%$ sodium hypochlorite between files. Chelating gel "Glide" (Dentsply) was used with all files. All instruments were discarded after being used in $5 \mathrm{MB}$ canals, and all canals were prepared by the same operator.

\section{Post-intrumentation scanning}

The instrumented canals were submitted to new CT scans, with the samples in the same position in the heavy body rubber base impression material mold and the same parameter settings described before. The data were stored on a magnetic optical disc. All CT images were assessed by a calibrated dental radiology specialist blinded to the order of teeth and root canal preparation techniques using Vitrea 2 V 3.8 imaging software (Vitrea 2, Vital Imaging Inc.) from root cross-sections at three levels; $3 \mathrm{~mm}$ from the apex (Apical), $3 \mathrm{~mm}$ from the canal orifice (Coronal), and mid way between the two measurements (Middle).

\section{Calculation Method}

From each cross section a1, a2, b1, b2 were measured at the three levels (apical, middle, and coronal) where a1 is the shortest distance between the mesial surface of the root and the uninstrumented canal, a2 is the shortest distance between the mesial surface of the root and the instrumented canal, b1 is the shortest distance between the distal surface of the root and the uninstrumented canal, and b2 is the shortest distance between the distal surface of the root and the instrumented canal. 
The centering ability ratio i.e the ability of the instrument to remain in a central position within the canal, was calculated for each cross-section using the ratio of (a1-a2) to (b1-b2) Whenever these numbers were not equal, the lower figure was considered to be the numerator of the ratio. According to this formula, a result of 1 indicates optimal centering ability.

Transportation was calculated for each crosssection using the equation (a1-a2)-(b1-b2). According to this formula, a result of 0 indicates no transportation ${ }^{[40,41]}$. Positive results indicate transportation distally, while a negative result indicates transportation mesially (Figure 1). All data collected were statistically analyzed.

\section{Statistical analysis of the data}

Data were fed to the computer and analyzed using IBM SPSS software package version 20.0. Comparisons between groups for categorical

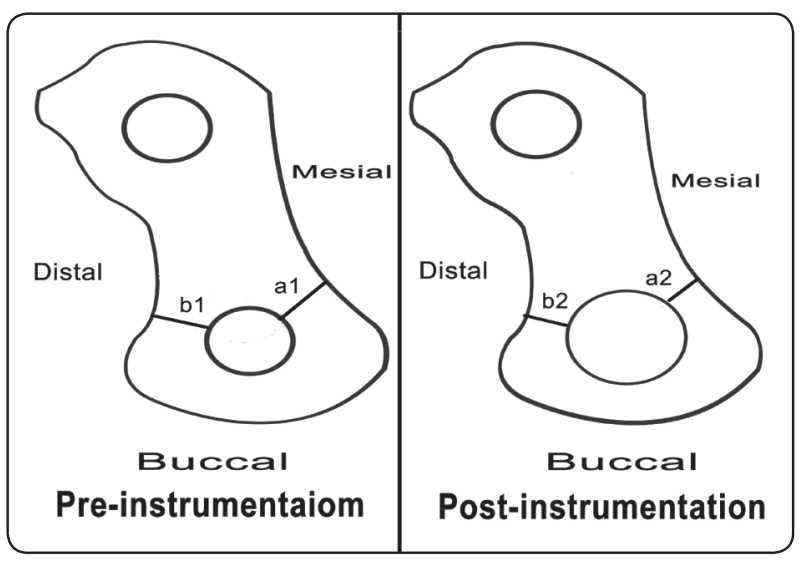

Fig. (1) Tooth sections showing how transportation and centric ability ratios were derived.

variables were assessed using Chi square test. Kruskal Wallis test was used to compare different groups for abnormally distributed quantitative variables and Mann Whitney test was used for comparing each two groups. Significance of the obtained results was judged at the $5 \%$ level.

\section{RESULTS}

\section{Centric ability results}

Centric ability was determined by the following formula: [(a1-a2)/(b1-b2)] or [(b1-b2)/(a1-a2)]. If these numbers are not equal, the lower figure is considered as the numerator of the ratio. According to this formula, a result of 1 indicates perfect centering.

In the apical part of the root, percentage of centric canals after instrumentation; in group I was $4 \%$, in group II was $4 \%$, in group III was $5 \%$, and in group IV was $6 \%$ with no significant difference between the four groups (Table 1).

In the middle part of the root, percentage of centric canals after instrumentation; in group I was $0 \%$, in group II was $0 \%$, in group III was $2 \%$, and in group IV was $5 \%$ with significant difference between the four groups. There was no significant difference between the group III and group IV. But, when comparing group I and II with group IV, there were a significant difference between them (Table 1).

In the coronal part of the root, percentage of centric canals after instrumentation; in group I was $4 \%$, in group II was $4 \%$, in group III was $3 \%$, and in group IV was $1 \%$ with no significant difference between the four groups (Table 1).

\section{Canal transportation results}

Canal transportation was determined by the following formula: [(a1-a2)-(b1-b2)] where a result other than 0 indicates canal transportation.

In the apical part of the canal, the mean values \pm standard deviation in group I was $(0.06 \pm 0.05)$, in group I was $(0.12 \pm 0.12)$, in group III was $(0.09$ $\pm 0.11)$, and in group IV was $(0.06 \pm 0.08)$ with no significant difference between the four groups (Table 2).

In the middle part of the canal, the mean values \pm standard deviation in group I was $(0.16 \pm 0.05)$, 
in group II was $(0.18 \pm 0.08)$, in group III was $(0.17$ $\pm 0.07)$, and in group IV was $(0.07 \pm 0.09)$ with a significant difference between the four groups. Also, there was a significant difference between group IV when compared with groups I, II, and III separately (Table 2).

In the coronal part of the canal, the mean values \pm standard deviation in group I was $(0.14 \pm 0.13)$, in group II was $(0.10 \pm 0.12)$, in group III was $(0.19$ $\pm 0.19)$, and in group IV was $(0.09 \pm 0.03)$ with no significant difference between the four groups (Table 2).

At the apical level, in ProTaper Universal group, four out of ten samples showed no transportation, four out of ten showed mesial transportation, and two out of ten showed distal transportation. While in ProTaper Next group, four out of ten samples showed no transportation, two out of ten showed mesial transportation, and four out of ten showed distal transportation. In WaveOne group,

TABLE (1) Comparison between the four different techniques according to centric ability

\begin{tabular}{|c|c|c|c|c|c|c|}
\hline Levels & $\begin{array}{l}\text { Centric } \\
\text { ability }\end{array}$ & $\begin{array}{c}\text { Group I } \\
\text { ProTaper Universal } \\
(\mathbf{n}=\mathbf{1 0})\end{array}$ & $\begin{array}{l}\text { Group II } \\
\text { ProTaper Next } \\
\quad(\mathbf{n}=\mathbf{1 0})\end{array}$ & $\begin{array}{l}\text { Group III } \\
\text { Wave One } \\
(\mathbf{n}=\mathbf{1 0})\end{array}$ & $\begin{array}{c}\text { Group IV } \\
\text { Wave One Gold } \\
(\mathbf{n}=\mathbf{1 0})\end{array}$ & $\mathbf{p}$ \\
\hline \multirow{2}{*}{ Apical } & Not centric & $6(60.0 \%)$ & $6(60.0 \%)$ & $5(50.0 \%)$ & $4(40.0 \%)$ & \multirow{2}{*}{0.899} \\
\hline & Centric & $4(40.0 \%)$ & $4(40.0 \%)$ & $5(50.0 \%)$ & $6(60.0 \%)$ & \\
\hline \multirow{2}{*}{ Middle } & Not centric & $10(100.0 \%)$ & $10(100.0 \%)$ & $8(80.0 \%)$ & $5(50.0 \%)$ & \multirow{2}{*}{$0.009^{\prime \prime}$} \\
\hline & Centric & $0(0.0 \%)$ & $0(0.0 \%)$ & $2(20.0 \%)$ & $5(50.0 \%)^{\mathrm{ab}}$ & \\
\hline \multirow{2}{*}{ Coronal } & Not centric & $6(60.0 \%)$ & $6(60.0 \%)$ & $7(70.0 \%)$ & $9(90.0 \%)$ & \multirow{2}{*}{0.437} \\
\hline & Centric & $4(40.0 \%)$ & $4(40.0 \%)$ & $3(30.0 \%)$ & $1(10.0 \%)$ & \\
\hline
\end{tabular}

Qualitative data were described using number and percent and was compared using Chi square test

*: Statistically significant at $p \leq 0.05$ a: Significant with group I b: Significant with group II

TABLE (2) Comparison between the four different techniques according to transportation

\begin{tabular}{|c|c|c|c|c|c|c|}
\hline Levels & Transportation & $\begin{array}{c}\text { Group I } \\
\text { ProTaper Universal } \\
(\mathbf{n}=\mathbf{1 0})\end{array}$ & $\begin{array}{c}\text { Group II } \\
\text { ProTaper Next } \\
\quad(\mathbf{n}=\mathbf{1 0})\end{array}$ & $\begin{array}{l}\text { Group III } \\
\text { Wave One } \\
(\mathbf{n}=\mathbf{1 0})\end{array}$ & $\begin{array}{c}\text { Group IV } \\
\text { Wave One Gold } \\
(\mathbf{n}=\mathbf{1 0})\end{array}$ & $\mathbf{p}$ \\
\hline \multirow{2}{*}{ Apical } & Mean \pm SD & $0.06 \pm 0.05$ & $0.12 \pm 0.12$ & $0.09 \pm 0.11$ & $0.06 \pm 0.08$ & \multirow{2}{*}{0.662} \\
\hline & Median (Range) & $0.10(0.0-0.10)$ & $0.10(0.0-0.30)$ & $0.05(0.0-0.360)$ & $0.0(0.0-0.20)$ & \\
\hline \multirow{2}{*}{ Middle } & Mean \pm SD & $0.16 \pm 0.05$ & $0.18 \pm 0.08$ & $0.17 \pm 0.07$ & $0.07^{\mathrm{abc}} \pm 0.09$ & \multirow{2}{*}{$0.034^{*}$} \\
\hline & Median (Range) & $0.20(0.10-0.20)$ & $0.20(0.10-0.30)$ & $0.20(0.0-0.30)$ & $0.05(0.0-0.30)$ & \\
\hline \multirow{2}{*}{ Coronal } & Mean \pm SD & $0.14 \pm 0.13$ & $0.10 \pm 0.12$ & $0.19 \pm 0.19$ & $0.09 \pm 0.03$ & \multirow{2}{*}{0.619} \\
\hline & Median (Range) & $0.20(0.0-0.30)$ & $0.10(0.0-0.30)$ & $0.15(0.0-0.50)$ & $0.10(0.0-0.10)$ & \\
\hline
\end{tabular}

Abnormally distributed data was compared using Kruskal Wallis test, comparisons between each two groups was assessed using Mann Whitney test.

*: Statistically significant at $\mathbf{p} \leq \mathbf{0 . 0 5}$

a: Significant with group I b: Significant with group II c: Significant with group III 
five out of ten samples showed no transportation, three out of ten showed mesial transportation, and two out of ten showed distal transportation. In WaveOne Gold group, six out of ten samples showed no transportation, two out of ten showed mesial transportation, and two out of ten showed distal transportation (Table 3).

At the middle level, in ProTaper Universal group, two out of ten showed mesial transportation, and eight out of ten showed distal transportation. While in ProTaper Next group, two out of ten showed mesial transportation, and eight out of ten showed distal transportation. In WaveOne group, two out of ten samples showed no transportation, one out of ten showed mesial transportation, and seven out of ten showed distal transportation. In WaveOne Gold group, five out of ten samples showed no transportation, two out of ten showed mesial transportation, and three out of ten showed distal transportation (Table 3).

At the coronal level, in ProTaper Universal group, four out of ten samples showed no transportation, four out of ten showed mesial transportation, and two out of ten showed distal transportation. While in ProTaper Next group, four out of ten samples showed no transportation, four out of ten showed mesial transportation, and two out of ten showed distal transportation. In WaveOne group, three out of ten samples showed no transportation, three out of ten showed mesial transportation, and four out of ten showed distal transportation. In WaveOne Gold group, one out of ten samples showed no transportation, three out of ten showed mesial transportation, and six out of ten showed distal transportation (Table 3).

TABLE (3) Number of samples with no transportation, mesial, and distal transportation in the four different techniques at apical, middle, and coronal levels

\begin{tabular}{|c|c|c|c|c|c|c|c|c|c|c|c|c|}
\hline \multirow[t]{2}{*}{ Levels } & \multicolumn{3}{|c|}{$\begin{array}{c}\text { Group I } \\
\text { ProTaper Universal } \\
(\mathrm{n}=10)\end{array}$} & \multicolumn{3}{|c|}{$\begin{array}{c}\text { Group II } \\
\text { ProTaper Next } \\
\quad(\mathrm{n}=10)\end{array}$} & \multicolumn{3}{|c|}{$\begin{array}{l}\text { Group III } \\
\text { Wave One } \\
(\mathrm{n}=10)\end{array}$} & \multicolumn{3}{|c|}{$\begin{array}{c}\text { Group IV } \\
\text { Wave One Gold } \\
(\mathrm{n}=10)\end{array}$} \\
\hline & No & Mesial & Distal & No & Mesial & Distal & No & Mesial & Distal & No & Mesial & Distal \\
\hline Apical & 4 & 4 & 2 & 4 & 2 & 4 & 5 & 3 & 2 & 6 & 2 & 2 \\
\hline Middle & 0 & 2 & 8 & 0 & 2 & 8 & 2 & 1 & 7 & 5 & 2 & 3 \\
\hline Coronal & 4 & 4 & 2 & 4 & 4 & 2 & 3 & 3 & 4 & 1 & 3 & 6 \\
\hline
\end{tabular}

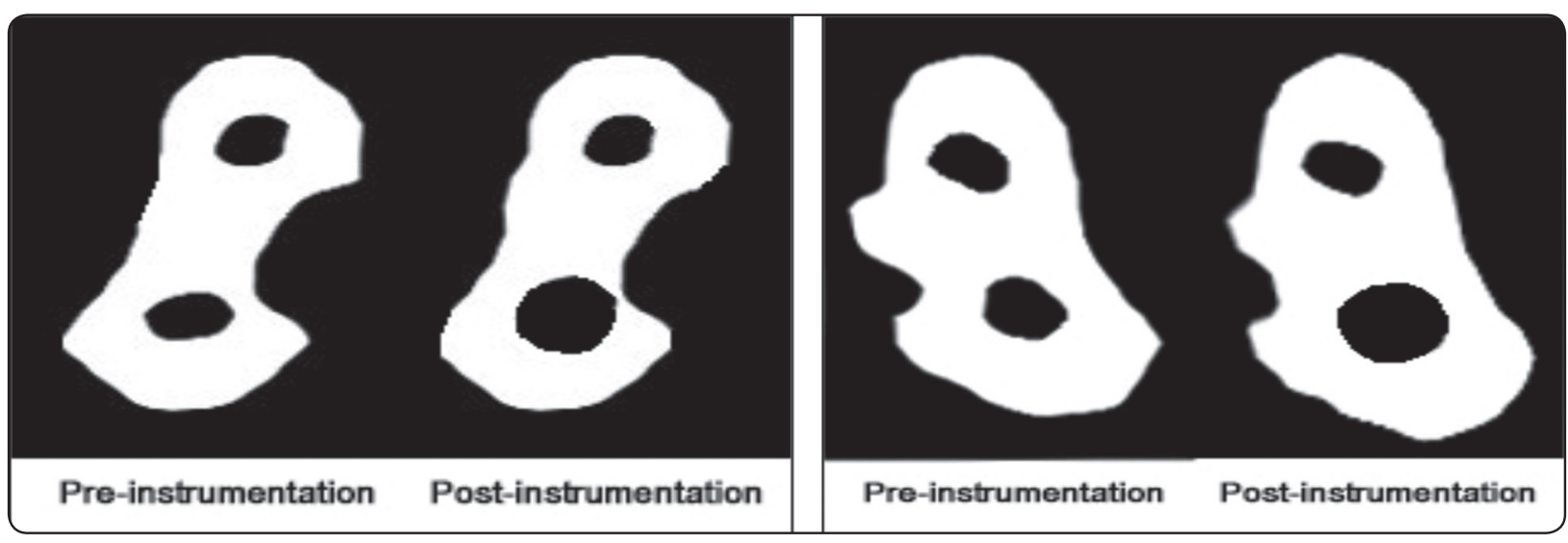

Fig. (1) CT scan images before and after instrumentation at different levels. 


\section{DISCUSSION}

The main objective in root canal preparation is to develop a taper shape from the apical to coronal with maintaining the original canal shape ${ }^{[42]}$. In curved canals, transportation occurs in different parts of the canal resulting in ledges, perforations or zipping with loss of its centric ability. This may prevent proper sealing of the obturation materials and facilitate reinfection from residual infected dentin or necrotic pulp ${ }^{[43]}$.

Research showed that, in spite of all developments in root canal instruments, all root canal preparation techniques produced canal transportation [44]. Whereas, introduction of NiTi rotary instruments had greatly improved the instrumentation of curved canals ${ }^{[13,45-48]}$. This was in accordance with the present work results that, the four systems under study caused varying degree of transportation.

Bergmans et al ${ }^{[49]}$ speculated that the flexibility of a file and instrumentation techniques such as early coronal enlargement are more important than the file type in achieving centered preparation of the apex. Increase taper of NiTi rotary instruments is related directly to the increased cross-sectional area and decreased flexibility. Also canal curvature, root canal anatomy, and anatomical diameter might be involved in apical transportation of the root canal ${ }^{[9]}$.

Four different NiTi rotary file systems (ProTaper Universal, ProTaper Next, WaveOne, and WaveOne Gold) were evaluated in the present study for centric ability and canal transportation after preparation of mesio-buccal canals of mandibular first molars with moderate curve up to apical size 25 for standardizaion.

Plastic models, cross sectioning and microcomputed tomography, scanning electron microscope and recently, cone beam computed tomography are methods to study canal transportation and centric ability ${ }^{[31-34]}$. In the present study, Multi-slice high resolution CT was used pre and post instrumentation to estimate the amount of deviation from the original shape in cross section of the root al apical, middle, and coronal levels. It is more accurate measurement software with capabilities of matching multidimensional data from samples before and after preparation. Determination of the amount of canal transportation and the centric ability ratio was done according to the equations used by Nagaraja et al ${ }^{[40]}$ and Gergi et al ${ }^{[41]}$.

It was found that, the percentage of centric canals after instrumentation was higher in Wave One Gold group followed by Wave One group, ProTaper Next group and the least percentage was ProTaper Universal group with no significant difference between them at the apical and coronal parts of the canal. But, in the middle part, there was a significant difference between them. This was in agreement with Capar et al ${ }^{[47]}$ who concluded that, all file systems straightened root canal curvature and produced canal transportation in the preparation of severely curved mesial canals of mandibular molars and reciprocating instrumentation exhibited superior performance.

The ProTaper Next was introduced in 2014 and the manufactures claimed that, these files' unique designs increase their centeric abilities and reduce transportation errors.

Both ProTaper next and WaveOne NiTi files are manufactured with M-Wire NiTi alloy which render endodontic instruments more flexible and fatigue resistant than those made with conventionally processed NiTi wires ${ }^{[25-28]}$. Because of the increased flexibility, the M-Wire NiTi alloy files may maintain the original canal shape better and minimize canal transportation in the curved root canals ${ }^{[29]}$. This was in accordance with our work results where the transportation occurred more in ProTaper Universal group with significant difference in the middle part of the canal which explained by the increased taper progressively along this type of file.

Dhingra et al ${ }^{[35]}$ concluded that, Protaper Next has better centric ability than WaveOne and Protaper Universal which is not consistent with the 
results of the current study and You et al ${ }^{[50]}$ who concluded that, the application of reciprocating motion during instrumentation did not result in increased apical transportation when compared with continuous rotation motion, even in the apical part of the curved canals. They stated that, reciprocating motion might be an attractive alternative method to prevent procedural errors during root canal shaping.

The results of the present study indicated that, the use of WaveOne Gold in a reciprocating motion in preparing moderate to severe curved canals will improve the canal preparation, keep its original anatomy, better centric ability with less canal transportation which was in agreement with Webber $\mathbf{J}^{\left[{ }^{51]}\right.}$ who stated that, WaveOne Gold instruments are manufactured utilizing a new thermal process, producing a super-elastic NiTi file. While this process gives the file its gold finishes and improves its strength and flexibility far in excess of its predecessor.

\section{CONCLUSION}

Within the limit of this study, the new WaveOne Gold NiTi primary reciprocating file maintained the original canal anatomy with less modification of the canal curvature compared with other file systems up to apical size 25 .

\section{REFERENCES}

1- Jou YT, Karabucak B, Levin J, Liu D. Endodontic working width: current concepts and techniques. Dent Clin North Am 2004; 48:323-35.

2- Peters OA. Current challenges and concepts in the preparation of root canal systems: a review. Endod J. 2004; 30:559-67.

3- Peters OA, Peters CI, Sch€onenberger K, Barbakow F. ProTaper rotary root canal preparation: assessment of torque and force in relation to canal anatomy. Int Endod J 2003; 36:93-9.

4- Pruett JP, Clement DJ, Carnes DL Jr. Cyclic fatigue testing of nickel-titanium endodontic instruments. Endod J.1997; 23:77-85.
5- Weine FS, Kelly RF, Lio PJ. The effect of preparation procedures on original canal shape and on apical foramen shape. Endod J 1975; 1: 255-62.

6- Endodontics. Ingle, Elsevier BC. 2002; 5th Ed: 775.

7- Kandaswamy D, Venkateshbabu N, Porkodi I, Pradeep G. Canal-centering ability: An endodontic challenge. Conserv Dent J 2009; 12:3-9.

8- Gianluca G. The K3 rotary nickel titanium instrument system. Endod Top 2005; 10:179-82.

9- American Association of Endodontists. Glossary of Endodontic Terms. 2003; Chicago: 7th ed AAE.

10- Loizides AL, Kakavetsos VD, Tzanetakis GN, Kontakiotis EG, Eliades G. A comparative study of the effects of two nickel-titanium preparation techniques on root canal geometry assessed by micro-computed tomography. Endod J 2007; 33:1455-9.

11- Jafarzadeh H, Abbott PV. Ledge formation: review of a great challenge in endodontics. Endod J 2007; 33:1155-62.

12- Davis RD, Marshall JG, Baumgartner JC. Effect of early coronal flaring on working length change in curved canals using rotary nickel-titanium versus stainless steel instruments. Endod J 2002; 28:438-42.

13- Glossen CR, Haller RH, Dove SB, del Rio CE. A comparison of root canal preparations using Ni-Ti hand, $\mathrm{Ni}$ - $\mathrm{Ti}$ engine-driven, and K-Flex endodontic instruments. Endod J 1995; 21:146-51.

14- Peters OA, Laib A, Gohring TN, Barbakow F. Changes in root canal geometry after preparation assessed by highresolution computed tomography. Endod J 2001; 27: 1-6.

15- Schafer E, Florek H. Efficiency of rotary nickel-titanium K3 instruments compared with stainless steel hand KFlexofile: part 1-shaping ability in simulated curved canals. Int Endod J 2003; 36:199-207.

16- Coleman CL, Svec TA. Analysis of Ni-Ti versus stainless steel instrumentation in resin simulated canals. Endod J 1997; 23: 232-5.

17- Kandaswamy D., Venkateshbabu N., Porkodi I., Pradeep G. Canal-centering ability: An endodontic challenge. Conserv Dent J 2009 Jan-Mar Vol 12: 3-9.

18- Ruddle CJ. The ProTaper technique: endodontics made easier. Dent Today 2001; 20:58-64,66-8. 
19- Peet J. van der Vyver \& Michael J. Scianamblo. Trends \& Applications. Clinical guidelines for the use of ProTaper Next instruments (Part I). Dental Tribune Asia 2014; Pacific Edition No. 7+8: 12-16.

20- Ruddle CJ. Canal Preparation: Single-File Shaping Technique. Endodontic 2012; 21:22.

21- You SY, Bae KS, Baek SH, Kum KY, Shon WJ, Lee W. Lifespan of one nickel-titanium rotary file with reciprocating motion in curved root canals. Endod J 2010; 36:1991-4.

22- Varela-Pati no P, Iba nez-P_arraga A, Rivas-Mundi na B, Cantatore G, Otero XL, Martin-Biedma B. Alternating versus continuous rotation: a comparative study of the effect on instrument life. Endod J 2010; 36:157-9.

23- Berutti E, Paolino D S, Chiandussi G, Alovisi M, Cantatore G, Castellucci A, Pasqualini D. Root Canal Anatomy Preservation of Wave One Reciprocating Files with or without Glide Path Endod J 2012; 38(1): 101-104.

24- Webber J, Machtou P, Pertot W, Kuttler S, Ruddle C, West J. The WaveOne single-file reciprocating system. Roots 2011; 1: 28-33.

25- Pereira ES, Gomes RO, Leroy AM, Singh R, Peters OA, Bahia MG, Buono VT. Mechanical behavior of MWire and conventional NiTi wire used to manufacture rotary endodontic instruments. Dent Mater. 2013 Dec; 29(12):e318-24.

26- Johnson E, Lloyd A, Kuttler S, Namerow K. Comparison between a novel nickel-titanium alloy and 508 nitinol on the cyclic fatigue life of ProFile 25/.04 rotary instruments. Endod J. 2008; 34:1406-9.

27- Larsen CM, Watanabe I, Glickman G. Cyclic fatigue analysis of a new generation of nickel titanium rotary instruments. Endod 2009 J; 35:401-3.

28- Al-Hadlaq SMS, AlJarbou FA, AlThumairy RI. Evaluation of cyclic flexural fatigue of M-Wire nickel-titanium rotary instruments. Endod J 2010; 36:305-7.

29- Tambe V.H., Nagmode P.S., Abraham S, Patait M., Lahoti P.V., and Jaju N. Comparison of canal transportation and centering ability of rotary protaper, one shape system and wave one system using cone beam computed tomography: An in vitro study Conserv Dent. J 2014 Nov-Dec; 17(6): 561-565.

30- Product News. Introducing the gold standard. Brit Dent J 2015 Volume 218 No. 8 Apr: 495.
31- Goldberg M., Dahan S, and Machtou P. Centering Ability and Influence of Experience When Using WaveOne Single-File Technique in Simulated Canals Inter Dent J Volume 2012 Article ID 206321, 7 pages.

32- Freire L.G., Gavini G., Cunha R.S., Santos M.D. Assessing apical transportation in curved canals: comparison between cross-sections and micro-computed tomography. Braz. oral res. 2012 vol.26 no.3 São Paulo May/June

33- Lim Y.J., Park S.J., Kim H.C., and Min K.S. Comparison of the centering ability of Wave-One and Reciproc nickeltitanium instruments in simulated curved canals. Restor Dent Endod. 2013 Feb; 38(1): 21-25.

34- Scarfe WC, Farmen AG -What is Cone-Beam CT and How Does it Work? Dent Clin N Am J 2008; 52 707-730.

35- Dhingra A., Gupta R., Singh A. Comparison of Centric Ability of Protaper Next, Wave One \& Protaper using Cone Beam Computed Tomography. Endodontology 2014 December; 26 Issue 2:244-251

36- Dhingra A., Nagar N., Sapra V. Influence of the glide path on various parameters of root canal prepared with WaveOne reciprocating file using cone beam computed tomography Dent. Res. J. 2015; Volume : 12 Issue : 6 Page: 534-540.

37- Gluskin AH, Brown DC, Buchanan LS. A reconstructed computerized tomographic comparison of $\mathrm{Ni}-\mathrm{Ti}$ rotary GT files versus traditional instruments in canals shaped by novice operators. Int Endod J 2001; 34:476-84.

38- Garip Y, Günday M. The use of computed tomography when comparing nickel-titanium and stainless steel files during preparation of simulated curved canals. Int Endod J 2001; 34:452-7.

39- Schneider SW. A comparison of canal preparations in straight and curved root canals. Oral Surg Oral Med Oral Pathol Oral Radiol Endod 1971; 32:271-5.

40- Nagaraja S, Murthy B V S.CT evaluation of canal preparation using rotary and hand NI-TI instruments: An in vitro study Conserv Dent J 2010 Jan-Mar; Vol 13 Issue 1:16-22.

41- Gergi R, Rjeily JA, Sader J, and Naaman A. Comparison of Canal Transportation and Centering Ability of Twisted Files, Pathfile-ProTaper System, and Stainless Steel Hand K-Files by Using Computed Tomography. Endod J 2010; 36:904-907.

42- Thomson SA, Dummer PMH. Shaping ability of Hero 642 rotary nickel-titanium instruments in simulated root canals: part 2. Int Endod J 2000; 33:255-61. 
43- Zuolo ML, Walton RE, Imura N. Histologic evaluation of three endodontic instrument/ preparation techniques. Endod Dent Traumatol 1992; 8:125-9.

44- Hartmann MS, Barletta FB, Camargo Fontanella VR, Vanni JR. Transportation after Root Canal Instrumentation: A Comparative Study with Computed Tomography Endod J 2007; 33:962-965.

45- Al-Sudani D, Al-Shahrani S. A comparison of the canal centering ability of ProFile, K3, and RaCe Nickel Titanium rotary systems Endod. J 2006 Dec; 32(12):1198-201.

46- Arora A, Taneja S, Kumar M. Comparative evaluation of shaping ability of different rotary NiTi instruments in curved canals using CBCT. Conserv Dent. J 2014 Jan; 17(1):35-9

47- Capar ID, Ertas H, Ok E, Arslan H, Ertas ET. Comparative study of different novel nickel-titanium rotary systems for root canal preparation in severely curved root canals. Endod J. 2014 Jun; 40(6):852-856

48- Celik D, Taşdemir T, Er K. Comparative study of 6 rotary nickel-titanium systems and hand instrumentation for root canal preparation in severely curved root canals of extracted teeth. Endod. J 2013 Feb; 39(2):278-82

49- Bergmans L, Van Cleynenbreugel J, Beullens M, Wevers M, Van Meerbeek B, Lambrechts P. Progressive versus constant tapered shaft design using NiTi rotary instruments. Int Endod J 2003;36:288-95.

50- You SY, Kim HC, Bae KS, Baek SH, Kum KY, and Lee WC Shaping Ability of Reciprocating Motion in Curved Root Canals: A Comparative Study with Micro-Computed Tomography Endod J 2011; 37:1296-1300.

51- Webber J. Shaping canals with confidence: WaveOne Gold single-file reciprocating system. Clinical Endodontics 2015; Nov 12:1-10 